\title{
Capital, controle social e participação autônoma dos trabalhadores no capitalismo em crise
}

\author{
Maria Cristina Soares Paniago \\ Universidade Federal de Alagoas (UFAL)
}

\section{Capital, controle social e participação autônoma dos trabalhadores no capitalismo em crise}

Resumo: O objetivo deste artigo é discutir a concepção de autonomia (fábricas ocupadas) e de controle social (participação nas instâncias do Estado) dos/pelos trabalhadores, depois de décadas de experimentos sociais, a partir dos anos 1990. Observa-se que tais experiências ao invés de fortalecerem a luta pela emancipação do trabalho tem-no levado à crescente subordinação aos interesses do capital e à perda de vantagens parciais antes adquiridas. Tal quadro agrava-se com a crise estrutural e a produção destrutiva que caracterizam o sistema do capital, colocando em cheque os fundamentos das concepções de autonomia, de controle e de participação social democrática que as orientam. A autodeterminação dos trabalhadores e, portanto, a real autonomia e a participação social, de acordo com a discussão proposta pelo artigo, são irrealizáveis nos marcos do sistema dominante.

Palavras-chave: Autonomia operária. Participação social. Controle social. Crise estrutural do capital. Emancipação humana.

\section{Capital, Social Control and Autonomous Participation of Workers in Capitalism in Crisis}

Abstract: The purpose of this article is to discuss the concept of autonomy (occupied factories) and social control (participation in the State apparatus) of and by workers, after decades of social experiments, since the 1990s. It notes that these experiences, instead of strengthening the struggle for the emancipation of work, have led to a growing subordination of workers to the interests of capital and to the loss of previously acquired partial advantages. This situation is aggravated with the destructive structural and production crisis that characterizes the capitalist system, questioning the foundations of the concepts of autonomy, control and democratic social participation that guide them. Self-determination of workers therefore involves true autonomy and social participation, and according to the discussion proposed by the article, these cannot be achieved under the dominant system.

Keywords: Worker autonomy. Social participation. Social control. Structural crisis of capital. Human emancipation. 


\section{Introdução}

Em uma sociedade de classe, o trabalho que produz natureza transformada e a posse dos meios de produção são atribuições distintas de um conjunto de indivíduos constituintes de classes sociais, definidas a partir da posição que ocupam na produção social da riqueza ${ }^{1}$.

Para que a produção capitalista pudesse se desenvolver, e obter o êxito produtivo que lhe assegurou a existência até nossos dias, foi preciso que a relação antagônica entre os indivíduos postos a cumprir o papel de força de trabalho (trabalhadores) e aqueles proprietários dos meios de produção (capitalistas) estivesse amparada por uma adequada estabilidade, só assegurada pela dominação eficaz do capital na esfera da política (Estado) e da produção material (unidades produtivas individuais).

O pleno funcionamento sociometabólico da sociedade capitalista exigia um controle centralizador (na esfera da política) e autoritário (na esfera da produção material da riqueza) diante da rebeldia e insubmissão dos trabalhadores em produzir os meios de sua própria dominação - mais-valia extraída da força de trabalho e apropriada pelo capitalista. Condições estas fundamentais para que o sistema do capital pudesse alcançar a forma mais avançada de extração de trabalho excedente já vista na história.

O inegociável despotismo sobre o trabalho, na base da produção, combinou-se com uma ilusão democrática do ordenamento jurídico-político liberal no âmbito do Estado. $\mathrm{O}$ antagonismo real entre o capital e o trabalho deveria ser ocultado pelo incentivo à participação de todos nos processos de decisão quanto aos destinos da sociedade. Ainda que a consumação do projeto capitalista de sociedade tenha levado algum tempo para se consolidar na história, a partir do século 20 ele demonstrou plenamente sua maturidade. Em particular, conseguiu articular adequadamente no Ocidente o controle sobre o funcionamento sociometabólico da sociedade com a participação democrática de todas as classes.

Enquanto, na primeira metade do século 20, puderam-se ajustar os interesses da expansão do capital a uma crescente participação política dos trabalhadores, e até mesmo uma maior integração destes no mercado de consumo em sua fase de crescimento e ocupação de novos territórios e mercados, o efeito ideológico desta aparente sintonia entre capitalismo e democracia ${ }^{2}$, constituída na base da política de negociação entre as classes, teve enorme utilidade na atenuação dos antagonismos de classe, e na continuidade das formas de exploração e de acumulação de capital até ali estabelecidas. Ao mesmo tempo em que se ampliavam o domínio e o controle sobre as relações de produção, maior envolvimento dos trabalhadores se dava na participação democrática no ordenamento social dominante. Os benefícios materiais da expansão do capitalismo e seu efeito imediato sobre o padrão de vida dos trabalhadores constituíam um forte argumento contra aqueles que alertavam sobre a sua incerta duração e a lógica imanente ao próprio sistema do capital, cuja acumulação da riqueza tem como pressuposto a crescente exploração do trabalho e a apropriação privada de cada vez maior parcela da riqueza social.

A estabilidade aparente do sistema do capital, com base nesta estratégia de crescimento, sofre uma inflexão brutal a partir da crise estrutural que eclodiu na década de 1970. A participação oferecida anteriormente às camadas populares não pode mais ser mantida na escala e na abrangência vistas no período de ascendência do sistema. As democracias constituídas, agora presentes na maior parte do mundo ocidental, passam a executar o plano de recuperação da lucratividade do capital global com a implementação do ideário neoliberal, tendo como principais políticas saneadoras da crise o aumento da produtividade, juntamente com a geração de desemprego em larga escala. A perda das vantagens materiais e de direitos do trabalho vai ser a pedra de toque dos efeitos sociais provocados pelas medidas neoliberais. A relação capital-trabalho tem que ser ajustada de forma autoritária às necessidades do sistema do capital, visando garantir maior liberdade de movimentação para o capital e o crescimento da produção de trabalho excedente, o que, por consequência, leva a uma maior exploração daqueles que trabalham.

Neste quadro de crise estrutural, as condições reais de participação social e da constituição de formas autônomas de controle operário sobre o capital, tema de nosso interesse, tornam-se ainda mais problemáticas. As lutas defensivas do trabalho, no decorrer da segunda metade do século 20, encontram barreiras cada vez maiores para realizarem mesmo os avanços mais pontuais. Para não dizer que a classe trabalhadora viu-se atordoada e fragilizada em sua capacidade de resistência, com a retirada de muitos dos ganhos do passado em que predominara a política de negociação de classe.

Desse modo, explicitarmos os desafios que a luta emancipatória do trabalho, expressa nas experiências de autogestão operária nas fábricas ocupadas ou nas formas de controle social representadas pela estratégia de participação social na esfera do Estado, em tempos de crise estrutural, assume ainda maior importância histórica. E exige do Serviço Social uma compreensão acurada das modificações provocadas pelas demandas do capital, para que possa melhor orientar a formação e a ação profissionais, e a pesquisa, no combate à crescente desigualdade social e à miséria, consequências sociais inevitáveis da crise.

Temos por objetivo identificar os limites ontológicos do controle operário e da participação social, com- 
prometidos com a realização de objetivos emancipatórios no interior da sociedade regida pelo capital. O desafio para compreendermos, sem temor, em tempos de refluxo da luta de classes, os limites das experiências de controle operário, social, nos quadros do sistema do capital, e de reconhecermos os fundamentos ontológicos da relação-capital, bem como os requisitos superadores de toda sorte de exploração, está colocado na ordem do dia.

\section{Confusão teórica e ilusão estratégica}

Há tempos, a questão do controle social sobre o Estado e do controle operário sobre o capital vêm atraindo atenção de pensadores marxistas e do movimento dos trabalhadores de um modo geral.

A questão do controle operário sobre o capital, na tradição marxista, é recolocada de forma incisiva durante os processos revolucionários que marcaram o início do século 20. Momento em que surgiram as primeiras formas de conselhos operários em que se combatia a propriedade privada, e exigia-se a transferência de todo poder aos trabalhadores organizados. No rastro do fim da Primeira Guerra, a Revolução Russa e a alemã vão colocar em prática as primeiras experiências de autogestão no século 20, bem como vão enfrentar o desafio de articular o poder operário nas diversas esferas de atividade social, política e de produção material. É nesse período, e depois nas experiências revolucionárias que circundaram a Segunda Guerra Mundial, como aconteceu na Itália, na Espanha (TRAGTENBERG, 1987) e na Hungria, que o debate teórico sobre o controle operário e as formas de autogestão ganhará maior substância e influenciará as estratégias futuras a serem implementadas pelos revolucionários do movimento internacional dos trabalhadores.

Muitas outras experiências de controle operário no mundo ocorrerão (Yugoslávia, Argélia, França, Polônia), e muitas alterações estratégicas e conceituais sobre o controle operário serão concebidas no decorrer do século 20, até que uma onda mais significativa atinja a América Latina.

No Brasil, nos anos 1970, vão predominar no movimento operário as comissões de fábrica da oposição sindical nos anos de resistência à ditadura. E, depois, com o surgimento dos partidos dos trabalhadores e dos movimentos sociais, nos anos 80 , o foco no controle social pelos trabalhadores, antes nas fábricas, vai se deslocar para uma gama mais ampla de movimentos sociais, locais e de micropoder.

Sob a influência do alegado fracasso do socialismo, com o fim da URSS, o esgotamento dos ganhos obtidos no Welfare State e da inviabilidade do projeto socialdemocrata do caminho gradual para o socialismo, o grande desafio revolucionário de constituição de formas autônomas de poder operário, como condição à superação da exploração e do capital, é abandonado por contingentes crescentes de intelectuais, partidos e movimentos sociais.

Ao mesmo tempo abandona-se a possibilidade revolucionária de superação do capital e adotam-se estratégias de conciliação entre o mercado e o socialismo, entre o trabalho e o capital, de aperfeiçoamento do capitalismo democrático e da formulação de alternativas de controle operário no interior do capitalismo, sem que se questionem as formas de opressão de classe exercida pelo capital e o seu Es$\operatorname{tado}^{3}$, pois permanecem atuantes e inatacáveis.

Não desaparecem as necessidades de organização autônoma dos trabalhadores e as de luta pela melhoria de suas condições de vida e de trabalho. Mas essas reivindicações podem, a partir destas concepções, ser realizadas no/pelo capitalismo, uma vez que não há mais a necessidade de confronto com as causas da miséria e da exploração, qual seja, a apropriação privada do produto do trabalho alheio. Não se trata mais de confronto de projetos alternativos de classe, mas de conflito de interesses entre cidadãos, cuja disputa restringe-se à repartição da riqueza social.

Dentro deste quadro, portanto, a mera constituição de um coletivo de proprietários privados (associativismo, cooperativas, fábricas ocupadas etc.) torna-se, de um modo geral, sinônimo de autonomia do trabalho diante das relações ainda estabelecidas pelo capital. A luta contra a exploração fica subordinada apenas ao seu caráter de luta anti-hierárquica, democrática, participativa, ou torna-se uma luta contra a alienação descolada de uma luta contra o capital. Quando não se vê envolvida em novas relações de dependência estabelecidas, e justificadas, com o Estado capitalista (DALLEMAGNE, 1976; GAUDICHAUD, 2004).

A crítica ontológica de Marx sobre os fundamentos do sistema do capital e as exigências revolucionárias colocadas para a superação da exploração do trabalho, o que envolve também as formas de luta e organização dos trabalhadores, foi abandonada ou minimizada. Predomina, então, uma transfiguração conciliatória dos confrontos inevitáveis e um empobrecimento teórico de conceitos fundamentais como o de propriedade privada, uma vez que se confunde a propriedade coletiva, ainda submetida à lógica do capital, com a propriedade social nos termos colocados por Marx (MARX, 1984). Observa-se um reducionismo do caráter essencial de conceitos teóricos, fundamentados na realidade concreta, como um meio de justificar as experiências de autogestão, nas quais permanecem decisivos os imperativos da tirania do mercado (e do capital) sobre o poder de decisão dos trabalhadores cooperativados. A confusão teórica aí se estabelece impunemente, pois se passa a utilizar 
de forma similar conceitos historicamente formulados sob fundamentos distintos e contrários ao que se pretende caracterizar. É o que verificamos, por exemplo, no uso de "trabalho associado", originalmente formulado por Marx (1977).

Caso, entre outros, de Vieitez e Dal Ri (2001, p. 36-37, grifo nosso) quando afirmam que as empresas de autogestão (EA) "não contribuem para a perpetuação do mercado de trabalho assalariado. A razão primordial para isso é que a EA está baseada sobre uma relação de trabalho distinta da relação capitalassalariamento. O trabalhador típico da autogestão é o associado e não o assalariado." Mais à frente, continuam: "o associado distingue-se do assalariado pelo fato de que o ato de associação concede-lhe estabilidade no posto de trabalho [...], observadas, evidentemente, a 'sobrevivência do empreendimento' e certas regras coletivamente estabelecidas". Todas essas ideias estão contidas no item 2 do capítulo 2 , denominado "A negação do mercado de trabalho assalariado".

Resta-nos perguntar: existe conquista de uma autêntica autonomia pelos trabalhadores quando o sucesso do seu empreendimento está condicionado aos critérios do lucro e do mercado? Pode-se falar em trabalho associado mudadas apenas as normas contratuais, mas mantidas as relações de mercado? De acordo com Marx, o trabalho associado pressupõe o rompimento com a lógica do capital, a superação deste modo de produção, e a retomada do poder de decisão, em todas as esferas da vida social, pelos trabalhadores livremente associados.

Adiciona-se a esse movimento outro que reduz a conquista da emancipação do trabalho e a crítica de Marx à propriedade privada à mera adoção de normas sociais democratizantes nos marcos do socialismo de mercado (ou socialismo democrático). O que temos visto, no entanto, nas experiências relatadas pela literatura específica é que a participação social permitida na esfera pública e seu pretenso caráter decisório não ultrapassa o caráter de "recomendação", que pode ser ou não levada em conta a depender dos interesses econômico-políticos dominantes, os quais, em geral, em nada vital se veem ameaçados pela presença de representantes populares nos conselhos consultivos ou gestores. Também nas fábricas ocupadas, as decisões tomadas pela participação democrática dos trabalhadores reunidos em assembleias não podem contrariar as imposições externas, objetivas da produção de mercadorias determinadas pelo mercado e pelo valor de troca.

Por último, a disseminação da propriedade coletiva, através do sistema cooperativo ou autogestionário proposto pela economia solidária (SINGER, 2003) entre outras, não nos parece venha favorecer a superação da ordem dominante do capital, mas "induz a classe trabalhadora a lutar por soluções fantasiosas, condu- zindo-a a uma forma de luta que uma longa e trágica história revelou ineficaz" (GERMER, 2006, p. 202).

Essas concepções, de alguma forma, influenciaram o movimento das fábricas ocupadas na América Latina. Em particular no Brasil, um movimento inovador de ocupação de fábricas pelos trabalhadores aparece a partir dos anos 1990. A reivindicação à participação decisória direta dos trabalhadores no processo de produção ganha força e torna-se uma alternativa de vida real e imediata à crise do capital e ao desemprego. A posse dos meios de produção pelos trabalhadores permite a experimentação de diversas formas de participação no processo de decisão coletiva no chão da fábrica, agora não mais sob o despotismo do patrão. $\mathrm{O}$ que antes era reconhecido como "controle do trabalho" pelos capitalistas, vai ser substituído pela "regulação do trabalho" (ainda trabalho abstrato, alienado) pelos próprios trabalhadores nas empresas autogestionárias, segundo a interpretação, a nosso ver equivocada, de Vieitez e Dal Ri (2001).

Tais experiências de autogoverno dos trabalhadores não são novas na história, mas, atualmente, revestem-se de um contexto histórico-social bastante diverso dos momentos revolucionários ou de instabilidade política profunda que caracterizaram as experiências da Revolução Russa e da alemã (LOUREIRO, 2006; MANDEL, 1974), das comissões de fábrica de Turin (DIAS, 2000; COUTINHO, 1986; GRAMSCI; BORDIGA, 1981) ou dos cordões industriais no Chile de Allende (GAUDICHAUD, 2004), mencionando-se apenas algumas das mais significativas.

O histórico das experiências precedentes tem constatado o insucesso do avanço da autonomia operária no interior do capitalismo, a despeito das sinceras energias investidas. Recorda-nos Mészáros (2004, p. 505),

[...] a triste história do movimento cooperativo que foi praticamente destruído pelo imperativo de se adaptar às regras operacionais da estrutura capitalista, apesar do profundo compromisso ideológico de muitos indivíduos e de grupos de trabalhadores.

A finalidade emancipatória deve visar à acumulação de forças no sentido do confronto e da eliminação do capital, e de seu controle social sociometabólico autoritário e incontestável. Do contrário, a renúncia ao projeto de transformação radical da sociedade é o passo inevitável, recolocando o reformismo clássico como o único horizonte do movimento operário, na medida em que a "reforma social - simples meio na luta de classes" acaba por se tornar o seu fim (LUXEMBURG, 1975, p. 7).

A transformação radical, de acordo com Mészáros (2004, p. 486, grifos do original), 
[...] deve conter, como um componente organizacionalmente articulado da estratégia geral, a 'negação prática materialmente eficaz' das estruturas reprodutivas dominantes, em vez de reforçálas através da 'economia mista' e de várias formas de 'participação' na reestabilização socioeconômica e política do capital em crise.

Neste sentido, é importante resgatarmos o verdadeiro significado de participação e os requisitos indispensáveis ao exercício de um controle social dos trabalhadores.

No atual contexto de crise estrutural, cabe indagar se essas experiências de autogoverno, em particular, as fábricas recuperadas ou cooperativas fabris, possuem algum elemento novo ou desempenham um novo papel, de caráter mais ofensivo na luta de classes, no sentido da emancipação. Ou, mesmo, se elas poderão obter êxito na atenuação do desemprego e se estabelecerem como unidades produtivas autônomas, sobrevivendo ao/no mercado. E, por fim, se elas, de fato, contribuem para um acúmulo de forças de classe no sentido da emancipação e da superação do capital.

$\mathrm{O}$ que se nota é um processo de "arrefecimento dos movimentos de fábricas recuperadas", em razão da redução de fábricas fechadas em decorrência da crise, e de "degeneração" das experiências mais avançadas na América Latina, por se afastarem dos objetivos da construção de uma alternativa à ordem do capital (NOVAES, 2007a). Uma avaliação mais consolidada do conjunto diversificado destas experiências e de seus resultados ainda está por ser feita. Todavia, tais indicações de esgotamento das experiências de autogestão pelos trabalhadores exigem uma investigação radical, profunda, sem medo de se enfrentar os mitos da participação democrática.

O que se pode verificar, de um modo geral, é que o poder, dito autônomo, está alienado da livre decisão dos indivíduos sociais, seja na participação no Estado, seja no processo de produção (e distribuição) na fábrica, pois permanece subordinado à produção de mercadorias, cuja finalidade é o valor de troca. Em nenhum momento é questionado, objetivamente, o fetichismo da mercadoria, que continua imperando sobre a vida (e o pseudopoder de decisão) dos homens.

Desse modo, o que se pode constatar é que o controle social do trabalho nada controla. Os parâmetros estruturais do capital ainda estão no comando da produção e da reprodução sociais. Condição esta expressa de forma esclarecedora nas máximas: "nós participamos, vocês participam, eles lucram...", ou "nós participamos, vocês participam eles decidem...". Situação propícia para que a "substância mistificadora" da estratégia reformista se imponha com toda força (MÉSZÁROS, 2007, p. 229).

Deixarmos passar este período de agitação e mobilização da classe trabalhadora sem realizarmos uma avaliação crítica profunda dos fundamentos, objetivos e resultados das fábricas recuperadas para a luta emancipatória, seria reincidir na mesma prática alienante que impediu o marxismo de realizar uma crítica radical das razões históricas do fracasso de seu projeto revolucionário no passado. E deixaríamos de contribuir para uma reconstituição de estratégias e táticas adequadas aos atuais desafios históricos impostos aos trabalhadores pela necessidade de uma ofensiva socialista, em período de crise estrutural. Esta é uma tarefa fundamental para a formulação de uma teoria de transição socialista adequada ao nosso tempo.

\section{Limites ontológicos à participação e ao controle autônomo dos trabalhadores}

A esta altura da exposição devemos, então, considerar se há como se enfrentar, ou colocar sob controle ${ }^{5}$, as condições de funcionamento do sistema do capital. Ou seja, em que medida os fundamentos ontológicos do capital permitem a ação de formas autônomas de organização e luta do trabalho, no sentido de fazê-lo atender às necessidades vitais e históricas do trabalho?

A história do desenvolvimento do capital, de suas fases mais primitivas até hoje, indica, segundo Mészáros (2002), que o capital é um modo de controle e não um título legal de controle. Expressa-se na propriedade constitucionalmente assegurada, mas não tem nela sua origem. Não se pode tratá-lo como uma "entidade material" ou "um mecanismo neutro" que possa estar na posse de um ou outro indivíduo aleatoriamente, pois o capital "é sempre uma relação social". Uma relação social fundada no trabalho social, no trabalho abstrato, cujo requisito histórico foi a completa separação - a quebra da unidade - do trabalho vivo e as condições objetivas de sua atividade produtiva. O capital encontra sua base de existência sobre a sujeição do trabalho vivo, ao mesmo tempo em que só pode apresentar-se como a contrapartida - como trabalho acumulado, objetivado e alienado do sujeito que trabalha. Marx (1861, 1864 apud MÉSZÁROS, 2002, p. 707) acentua o caráter fetichizado desta relação, uma vez que "o produto" se torna "o proprietário do produtor".

Para que o capital possa cumprir sua função de controle do metabolismo social, não basta submeter o trabalho, tem que garantir o exercício do "total comando sobre o trabalho". Exercer permanentemente o "comando objetivado e alienado sobre o trabalho", de acordo com a análise desenvolvida por Mészáros (2002, p. 609), é uma "condição crucial para a existência e o funcionamento do capital." Tal "comando" só pode ser "exercido de modo indivisível pelo capital e por mais ninguém, sob quaisquer que 
sejam suas formas existentes e possíveis [...]. Sem ela, o capital deixaria de ser capital e desapareceria da cena história." Mesmo o capitalista submete seus desejos e vontades aos imperativos reprodutivos do capital. Enquanto personificação do capital, só se mantém capitalista se souber operar com êxito a lógica da acumulação e expansão contínuas. O que está em questão não é se as decisões necessárias ao funcionamento contínuo do sistema são ou não tomadas pelas personificações do capital, mas se essas controlam o sistema ou, pelo contrário, são controladas pelas "exigências fetichistas do sistema do capital enquanto tal".

O poder do capital afirmou-se por meio de novas modalidades de comando, inviabilizando qualquer alternativa de poder compartilhado, ou, por fim, integralmente assumido pelo trabalho.

Ocorre que na relação de dominação que estabelece com o trabalho alienado usurpa do sujeito real da produção todo poder de decisão e substitui as necessidades humanas conscientemente definidas por seus "próprios ditames e imperativos materiais cegos" de autovalorização (MÉSZÁROS, 2002, p.130/ 352). Entre tais "ditames e imperativos materiais cegos" está seu critério de produtividade, sempre orientado, segundo Marx, pela “"compulsão para produzir trabalho excedente', em trabalhar para além das necessidades do indivíduo". Nesse contexto, como diz Marx (1861 apud MÉSZÁROS, 2002, p. 129-130), “o processo de trabalho mesmo só aparece como um meio para o processo de valorização, assim como o valor de uso do produto somente aparece como veículo de seu valor de troca". Desaparece, assim, a prioridade da necessidade humana e da produção de valores de uso e, junto com ela, o poder de decisão dos trabalhadores sobre o conjunto de sua atividade socioprodutiva.

Qualquer tentativa de quebrar o antagonismo entre o capital e o trabalho, ou de se instituir um controle sobre apenas parte de seu sistema orgânico, sem que junto a isso se reestruture alternativamente toda a lógica reprodutiva do sistema - o que implica criar "um novo 'sistema orgânico' [...] genuinamente socialista e sustentável” (MÉSZÁROS, 2002, p. 726, grifo do original) -, só pode resultar em fracasso.

Muito além de necessitar de um reconhecimento jurídico-legal para desempenhar sua função de controle sobre a produção e reprodução sociais, o que se constata é que o "poder real de controle do capital permanece profundamente encravado nas estruturas materiais" da sociedade. Não obedece a nenhum tipo de autoridade que não esteja em consonância com suas necessidades de autoexpansão, subordinando toda a reprodução social a estes critérios, inclusive a força de trabalho utilizada, transformada em "custos de produção". Não suporta qualquer ato autônomo dos indivíduos que contrarie sua lógica reprodutiva. "Ele não pode, de modo algum, entregar sequer 'parte' de seu modo de controle - alienado, aprioristicamente determinado e, por sua própria natureza, 'irrestritamente totalizante' - [...] sem abolir a si próprio" (MÉSZÁROS, 2004, p. 514, grifos do original).

Tais imperativos reprodutivos do sistema do capital constituem sua forma de existência e determinam a ordem histórico-social sob seu predomínio.

Em função destes determinantes de sua forma de ser, "o controle social do capital é a priori uma impossibilidade em um sistema social em si controlado 'pelo' capital" (MÉSZÁROS, 2004, p. 514, grifos do original).

É desse modo que o capital exerce todo o poder sobre o conjunto da sociedade. É sua lógica autorreprodutiva (valor que gera valor) que organiza tanto a produção, como a distribuição da riqueza social. Conta, para isso, com a eficiente ação do Estado que lhe dá as garantias políticas para a sua reprodução ampliada, controlando a relação antagônica que caracteriza a exploração do trabalho, bem como complementando, na base material, os investimentos requeridos pelo desenvolvimento da produção e, na circulação, absorvendo parte da oferta de bens e serviços necessários à realização da lucratividade.

A grandeza do capitalismo nos últimos séculos deveu-se à sua capacidade de ampliar, de forma inigualável, a capacidade produtiva da atividade humana, universalizando a exploração do trabalho assalariado, sob um regime de poder autoritário na esfera produtiva, com a imposição dos imperativos cegos da expansão contínua e do lucro crescente. $\mathrm{O}$ sistema do capital só pôde funcionar mediante o domínio hierárquico absoluto na produção da riqueza, destruindo todas as barreiras arcaicas de produção e a resistência dos trabalhadores à submissão ao trabalho alienado. 
Uma vez que possui a força econômica na esfera da produção, atua, a partir dela, como força hegemônica na regulação jurídico-legal de toda a sociedade. Nas palavras de Mészáros (2002), é portador de uma força extraparlamentar que lhe assegura a direção política na esfera da participação parlamentar e dos órgãos do Estado em geral. Neste sentido, "todos os poderes significativos estão em posse do próprio capital", e não podem ser divididos entre "classes sociais concorrentes." À oposição de classe ao capital resta uma "margem de ação estreitamente circunscrita", como vemos no espaço da ação parlamentar (MÉSZÁROS, 2007, p. 230).

Se as restrições na esfera da política institucional são intransponíveis, no sentido de mudanças estruturais radicais em favor da emancipação do trabalho, considerar a possibilidade de se adquirir o poder político pouco a pouco através da luta institucional é ainda mais ilusório, pois “o poder político se constitui numa fraude se os trabalhadores não detêm o poder no campo da produção" (TRAGTENBERG, 1987, p. 23).

A participação dos trabalhadores (a autonomia, a iniciativa, a auto-organização, o poder de decisão real) está subordinada aos imperativos reprodutivos do sistema do capital ${ }^{6}$. O real poder de decisão dos trabalhadores só pode se realizar com o deslocamento e a eliminação do poder do capital. Não há possibilidade de coexistência pacífica entre poderes hegemônicos em confronto, pois não há coincidência de interesses de classe, nem espaço para colaboração de classes ${ }^{7}$. Nem mesmo em espaços de pequena escala, como nas experiências autogestionárias isoladas ${ }^{8}$ ou em conselhos populares. $\mathrm{O}$ "controle apenas localmente [...] é uma contradição nos termos, já que as decisões locais são sujeitas à aprovação ou sujeição em um nível estruturalmente resguardado e, por isso, necessariamente conflitual/adverso, mais alto" (MÉSZÁROS, 2007, p. 231).

Para a construção de uma sociedade emancipada (socialista), a participação só adquire um real significado "se os poderes de decisão forem realmente transferidos aos 'produtores associados' em todos os níveis e em todos os domínios." Os "produtores associados" devem adquirir o "controle do processo sociometabólico em sua integridade e em todos os níveis" e reassumir a função de "sujeito real do poder" (MÉSZÁROS, 2007, p. 230-231).

A questão fundamental é que o capital só pode funcionar com êxito instituindo um modo de controle metabólico social incontrolável, porquanto, orientado para a expansão contínua e a acumulação compulsiva, a despeito do caráter de produção destrutiva que tem imprimido em sua atual fase de desenvolvimento, provocado pela crise estrutural. Portanto, a superação do sistema do capital implica na recuperação pelo trabalho do real poder de decisão em todas as esferas da produção e reprodução sociais. O controle social a ser adquirido pelo trabalho coloca-se como requisito fundamental à conquista da emancipação humana, pois é requerido como alternativa hegemônica ao equivalente controle social hierárquico e autoritário do capital exercido sobre o trabalho. Não há possibilidade de compartilhar-se poder com o capital ${ }^{9}$.

O sistema do capital inicia o século 21 com um aprofundamento das contradições imanentes ao seu modo de ser, uma vez que as medidas saneadoras da crise instituídas nos últimos 30 anos, através do que se passou a denominar de neoliberalismo, surtem cada vez menor efeito, além de provocarem o agravamento das contradições devido aos problemas estruturais não resolvidos. Afinal, o capital não pode tratar das causas que provocam as contradições do sistema enquanto causas, apenas dos seus efeitos e consequências.

Mészáros (2002, p. 557-558) afirma que, por esta razão, "os limites últimos" do sistema do capital "sempre permanecem em operação". Uma vez que eles "operam subjacentes a todos os ajustes e circunscrevem o alcance das opções viáveis, impedindo enfaticamente a reversão bem-sucedida das próprias tendências fundamentais." O deslocamento das contradições imanentes ao sistema do capital exige recursos cada vez maiores como condição à recuperação econômica e ao controle político necessários, numa situação em que são "limitados pela redução crescente e ameaçadora da lucratividade".

\section{Desafios históricos do presente}

Diante deste quadro histórico, da afirmação inconteste da produção destrutiva como modus operandi do sistema do capital, a possibilidade de haver um futuro para a humanidade coloca a necessidade urgente de uma alternativa social hegemônica que supere a ordem dominante. Isso exige da classe operária a reconstituição de uma estratégica e organização revolucionárias, orientadoras de toda luta emancipatória empreendida, que a leve a acumular forças no confronto com o capital, independentemente de garantias de vitórias imediatas.

Desse modo, a investigação sobre a participação e o controle social a serem exercidos pelos trabalhadores não pode perder de vista sua finalidade emancipatória e nem deixar de reconhecer os requisitos fundamentais para a construção de uma sociedade socialista verdadeiramente autônoma, condições para que não nos confundamos com formas de pseudoparticipação e de pseudocontrole e nem nos conformemos por serem estas as únicas possíveis no interior dos quadros estruturais do capitalismo.

As experiências conselhistas ${ }^{10}$ ou de autogestão ${ }^{11}$ têm demonstrado, nas últimas décadas no Brasil, que ocupar espaços no Estado ou apenas possuir a pro- 
priedade dos meios de produção, mantidas as demais condições materiais de dominação e exploração do capital, não têm proporcionado a criação de esferas de autonomia para o trabalho, pois continuam subordinados à política dominante do capital e à tirania do mercado.

Não basta ambicionar democratizar o capitalismo, o desafio é a superação do capital. Este é o princípio orientador de toda luta de classes, e estimulador de formas mais criativas e eficazes de participação e combate do trabalho nos diversos espaços político-sociais. $\mathrm{O}$ que exige a construção de bases prático-teóricas autênticas, que se contraponham ao rebaixamento teórico da classe trabalhadora, e evitem a acomodação e o conformismo diante das conquistas parciais possíveis, importantes, mas que permanecem aprisionadas pelos determinantes reprodutivos do capital, o que as torna absolutamente insuficientes para a verdadeira reconstituição do real poder de decisão dos verdadeiros sujeitos da produção. Trata-se da adoção de estratégias ofensivas que extravasem o campo do passado defensivo, superado pelo amadurecimento das contradições do próprio sistema.

Em vista do caráter destrutivo e perdulário da produção imposta a toda a sociedade pela reprodução ampliada do capital em crise e os nefastos custos sociais provocados pelo desemprego estrutural e pela consequente degradação da condição de existência humana, ampliados à escala planetária (não se pode negar os dados assustadores sobre a fome no mundo), a constituição de uma forma alternativa de sociedade ao sistema do capital, que contemple a igualdade real entre todos os homens e uma produção e distribuição de riqueza humanamente autodeterminadas, é uma necessidade imperativa dada à ameaça de destruição da própria humanidade.

A "radical eliminação do capital pelos indivíduos autoemancipados de sua presente dominação do metabolismo social é o exato conteúdo do projeto socialista” (MÉSZÁROS, 2004, p. 516).

\section{Referências}

BRAVO, M. I. S. Desafios atuais do controle social no Sistema Único de Saúde. Serviço Social \& Sociedade, São Paulo: Cortez, n. 88, p. 75-100, 2006.

COUTINHO, C. N. Introducción a Gramsci. México: Ediciones Era, 1986.

DALLEMAGNE, J-L. Autogestion ou dictature du prolétariat. Paris: Union Générale D’Éditions, 1976.

DIAS, E. F. Gramsci em Turim. A construção do conceito de hegemonia. São Paulo: Xamã, 2000.
ENGELS, F. A origem da família, da propriedade privada e do Estado. Rio de Janeiro: Civilização Brasileira, 1979.

GAUDICHAUD, F. Poder popular y cordones industriales. Testimonios sobre el movimiento popular urbano, 1970-1973. Santiago: Lom ediciones, 2004.

GERMER, K. A economia solidária: uma crítica marxista. Outubro: Revista do Instituto de Estudos Socialistas, São Paulo: Alameda, n. 14, p. 51-74, 2006.

GRAMSCI, A.; BORDIGA, A. Os conselhos de fábrica. São Paulo: Brasiliense, 1981.

LOUREIRO, I. Os Conselhos na Revolução Alemã de 1918/19. Crítica Marxista, São Paulo: Editora Revan, n. 23, p. 97-110, 2006.

LUXEMBURG, R. Reforma, revisionismo e oportunismo. Rio de Janeiro: Civilização Brasileira, 1975.

MANDEL, E. Control obrero, consejos obreros, autogestión. México: Ediciones Era, 1974.

MARX, K. O capital. São Paulo: Abril Cultural, 1984. (v. 3, t. 1).

. Glosas críticas marginais ao artigo "O Rei da Prússia e a Reforma Social. De um Prussiano". Tradução de Ivo Tonet. Revista Praxis, Belo Horizonte: Projeto Joaquim de Oliveira, n. 5, out./dez., 1995.

. A guerra civil na França. Textos. São Paulo: Edições Sociais, 1977. (v. 1).

MÉSZÁROS, I. Para além do capital. Tradução de Paulo Cezar Castanheira e Sérgio Lessa. São Paulo: Boitempo, 2002.

O poder da ideologia. Tradução de Paulo Cezar Castanheira. São Paulo: Boitempo, 2004.

O desafio e o fardo do tempo histórico. Tradução de Ana Cotrim e Vera Cotrim. São Paulo: Boitempo, 2007.

NOVAES, H. T. O fetiche da tecnologia. A experiência das fábricas recuperadas. São Paulo: Fapesp, 2007.

. De tsunami a marola: uma breve história das fábricas recuperadas na América Latina. Lutas e Resistências, Londrina: UEL, n. 2, p. 84-97, 2007a.

PANIAGO, M. C. Mészáros e a incontrolabilidade do capital. Maceió: Edufal, 2007.

Os meios que se perderam dos fins: cooperativas fabris e autogestão dos trabalhadores. Outubro, Revista do Instituto de Estudos Socialistas, São Paulo: Alameda, n. 17, p. 207-230, 2008. 
SINGER, P. Introdução à economia solidária. São Paulo: Fundação Perseu Abramo, 2003.

TRAGTENBERG, M. Uma prática de participação: as coletivizações na Espanha (1936-1939). In: VENOSA. R. (Org.). Participação e participações: ensaios sobre autogestão. São Paulo: Babel Cultural, 1987.

Administração, poder e ideologia. São Paulo: Editora Moraes, 1980

TROTSKY, L. La revolución permanente. Buenos Aires: Ed. Yunque, 1977.

VIEITEZ, C. G.; DAL RI, N. M. Trabalho associado: cooperativas e empresas de autogestão. Rio de Janeiro: DP\&A Editora, 2001.

\section{Notas}

1 Este texto serviu de base para uma comunicaçãocientífica apresentada na International Labour Process Conference 2010, na Rutgers University, New Brunswick, New Jersey, USA. Constitui parte da pesquisa da autora para o pós-doutorado em Serviço Social, realizado na PUC-SP, entre 2010 e 2011.

2 Esse processo não se deu de forma linear e simultânea nos diversos continentes. Ao contrário, os países avançados puderam usufruir mais rápida e intensamente das vantagens da fase expansionista do capital, oferecendo aos países periféricos a promessa da modernização e do desenvolvimento crescentes (que, aliás, não se realizou) ainda que, na maioria dos casos, esta viesse associada a formas ditatoriais de dominação política. Num momento posterior, este processo expansionista entrou em crise e as mudanças democráticas na periferia do mundo, ainda que tardiamente, vieram cumprir uma função equivalente na sustentação da acumulação do capital social global. Tantonummomento, comonoutro, a relaçãoestabelecidaentre países avançados e periféricos pode ser melhor compreendida se pensarmos que ambos constituem a totalidade do sistema do capital global, regido pela lei do desenvolvimento desigual e combinado, conforme formulação clássica de Trotsky (1977), após Marx.

3 Quanto à concepção de Estado, a referência teórica encontra-se em Marx (1995), Engels (1979) e Mészáros (2002)

4 VerTragtenberg (1987).

5 A fundamentação teórica sobre a incontrolabilidade do capital, tese desenvolvida por Mészáros em Para além do capital, pode ser encontrada em estudo realizado por Paniago (2007).

6 Uma análise crítica sobre os limites da construção da autonomia operária no seio do capitalismo, a partir de experiências concretas de autogestão e cogestão no Brasil, pode ser encontrada em Paniago (2008).
7 Base em que funcionaram as experiências de cogestãoe de conselhos operários na Europa Ocidental, no período do Welfare State, em que leis do Estado regulamentaram a coparticipação e a colaboração entre patrões e operários na gestão de empresas (TRAGTENBERG, 1980).

8 Para Marx, "a experiência do período decorrido entre 1848 e 1864 provou acima de qualquer dúvida que, por melhor que seja em princípio, e por mais útil que seja na prática, o trabalho cooperativo, se mantido dentro doestreito círculo dos esforços casuais de operários isolados, jamais conseguirá deter o desenvolvimento em progressão geométrica do monopólio, libertar as massas, ou sequer aliviar de maneira perceptível o peso de sua miséria" (MARX, 1975 apud GERMER, 2006, p. 209).

9 Sem a "total eliminação do capital, tanto das microestruturas em cujo interior as práticas produtivas e distributivas da sociedade são realizadas, quanto do modo como estão articuladas em um todo coerente", a "autoatividade conscientemente planejada dos produtores associados no plano de seus intercâmbios abrangentes se tornariaimpossíveloque, por sua vez, prejudicariainevitavelmente seus esforços para instituir a autogestão autônoma da atividade produtiva no local de trabalho" (MÉSZÁROS, 2004, p. 516).

10 Ver Bravo (2006).

11 Ver Novaes (2007)

\section{Maria Cristina Soares Paniago} mcristinapaniago@yahoo.com.br Pós-Doutoramento em Serviço Social na PUC-SP Doutora em Serviço Social pela Universidade Federal do Rio de Janeiro (UFRJ) Professora associada da Faculdade de Serviço Social na Universidade Federal de Alagoas (UFAL)

\section{UFAL - Faculdade de Serviço Social}

Campus A. C. Simões

Av. Lourival Melo Mota, s/n

Bloco 16, andar térreo

Tabuleiro do Martins

Maceió - Alagoas

CEP: $57072-970$ 